\title{
Technological development for the reduction of out-of-plane deformation of metallic meander structures in thermoformed electronics
}

\author{
Behnam Madadnia $^{1}$. Frederick Bossuyt ${ }^{1}$. Jan Vanfleteren ${ }^{1}$
}

Received: 29 July 2021 / Accepted: 4 January 2022 / Published online: 22 January 2022

(c) The Author(s) 2022

\begin{abstract}
This paper presents a novel approach for removing out-of-plane deformation in stretched metal interconnects by adding a fractal structure to the original meander shape and using an optimized fabrication stack. In thermoformed electronics, in cases where copper is used as conductor, the twisting of meander-shaped structures caused by excessive mechanical stress can cause a non-uniform surface, delamination of the metal interconnect from the substrate, and in some cases, a short circuit to the adjacent tracks. Typically, designers of stretchable electronics use various shapes and widths of the copper interconnect to tackle this issue. Using conventional meander shapes such as horseshoes and U-shapes is not universally practical, especially when stretching is higher than 30 percent leading to significant out-of-plane buckling. Limiting this out-of-plane buckling by reducing the track width is not always applicable, as a minimum width is needed from a technology and conductivity perspective. The presented approach is inspired by computational and experimental studies of multiple meander shapes and fabrication methods. A geometry- and fabrication-based approach is presented, reducing the mechanical stress of almost all possible meander shapes by increasing the meander's path length to accommodate the metal track's produced torque during stretching. An analytical approach is provided for calculating the optimal meander parameters and the optimal fabrication stack is achieved based on simulation results. Experiments and finite element modeling for a case study show the improvement in the stress distribution and reduction of out-of-plane buckling.
\end{abstract}

Keyword Out-of-plane buckling—-Meander structure-Thermoformed electronics

\section{Introduction}

Thermoplastic electronics have surged in popularity in the automotive, aerospace, lighting, and biomedical industries. Two technologies have been introduced to fulfill multiple challenges in this area. In-mold electronic technology $[1,2]$ uses stretchable and thermoformable inks printed on a thermoplastic substrate to deal with significant deformation during

Jan Vanfleteren

jan.vanfleteren@ugent.be

Behnam Madadnia

behnam.madadnia@ugent.be

Frederick Bossuyt

Frederick.Bossuyt@UGent.be

1 Centre for Microsystems Technology, Imec and Ghent University, Technology Park 126, B-9052 Gent-Zwijnaarde, Belgium thermoforming. Another method presented by our research group is stretchable mold interconnect (SMI) [3, 4], which is the main focus of this article. In this approach, the main idea is to use two-dimensional metal springs as conductor structures to accommodate stretching during thermoforming. In this technology, designing optimal metal interconnections, which can accommodate high stretching without mechanical buckling and rupture, is critical. Gonzalez [5] compared different conductor structure shapes for metallic stretchable interconnections and presented a horseshoe-shaped meander as the optimal shape. Hsua [6] introduced a novel metal interconnection shape. A zigzag-patterned structure is presented based on an analytical and numerical analysis that enables stretchability up to $62 \%$ without rupture. For higher stretching, out-of-plane deformation and delamination from the substrate are reported Fig. 1. Hsu [7] presented an optimized design for metal interconnects comprised of $\mathrm{Cu}$ and polyimide support. It was demonstrated that polyimide width and thickness could dramatically affect the strain distribution on crest regions. Optimal values for 
polyimide thickness and width are obtained. Xu [8] presented a deformable interconnect with an advanced design using a serpentine configuration, offering a high level of stretchability and low interconnect resistance. These interconnects can accommodate up to 300 percent elongation without rupture, but we can see out-of-plane deformation for stretching higher than 50 percent. Chtioui [3] optimized the design parameters for horseshoe-shaped meander structures as the conductor tracks on a thermoformable substrate. Various radii and angles for horseshoe meanders have been fabricated and thermoformed. In the regions with high elongation, delamination of the copper from the substrate caused by out-of-plane buckling is reported. Ma [9] presented in 2016 a fractal design for horseshoe-shaped meanders, which has improved the elastic stretchability four times compared to the conventional horseshoe design. A theoretical model is developed to study the nonlinear stress-strain curves and elastic stretchability. Biswas [10] reported a stress-adaptive metal interconnect design with two different widths along the meander to accommodate the metal tracks' produced strain during stretching. Plovie [11] presented a generic approach for analyzing three conventional meander types: horseshoe, U-shape, and triangular. This paper focuses on finding the meander's path length and the actual meander length after stretching.

From an application point of view: out-of-plane deformation of meanders under stretch also happens in dynamically deformable (elastic) circuits and might cause delamination and limited reliability, but does not significantly influence product look or quality. However, with thermoformed electronics, the out-of-plane deformation of meanders is permanent (after stretching by thermoforming, the stretched interconnections and out-of-plane deformed meanders remain in this state). This out-of-plane deformation of the meanders causes a deformation of the embedding polymer and a product's non-smooth surface, which should be avoided. To the best of our knowledge, there is no study of out-of-plane buckling in thermoformed electronics for obtaining the best meander design parameters (suitable for fabrication and not too complex geometry) with minimum out-of-plane buckling.

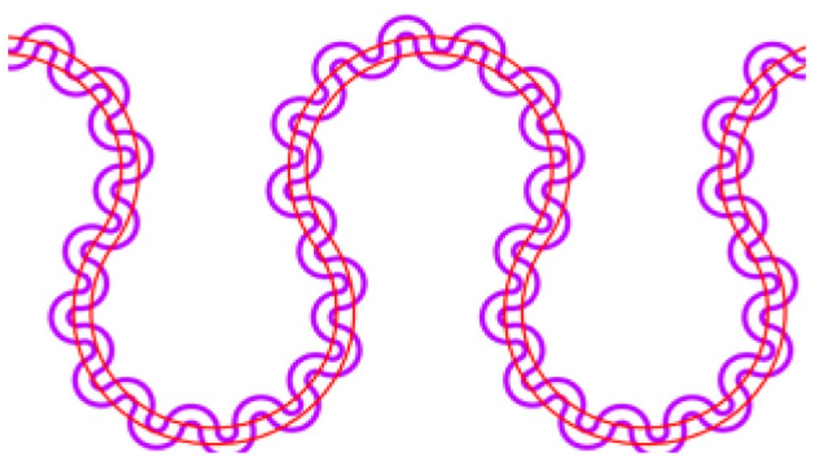

Fig. 2 Fractal structure added to the original meander

This paper proposes a geometry- and fabricationbased optimization approach for reducing out-of-plane deformation in thermoformed electronics. Based on the literature, we have introduced a horseshoe meander shape as the best candidate as a baseline for our optimal meander design. First, we present a fractal-based design in the geometry-based method as depicted in Fig. 2, increasing the original meander's length. Based on [12], there is an inverse relationship between the meander's length and the maximum strain across the meander. Out-of-plane deformation is a direct consequence of stress build-up in the meanders when elongated, which means that the out-of-plane deformation decreases by increasing the meander's length. The next part investigates the fabrication parameters such as copper and polyimide thickness and finds the best fabrication parameters for having minimum out-of-plane deformation. Fig. 1.

\section{Methods and materials}

The design rules of the fractal meander design will be explained in the geometry-based approach and the stack selection of the meander will be discussed in the fabricationbased approach.
Fig. 1 Out-of-plane deformation in a thermoformed sample, which has caused delamination

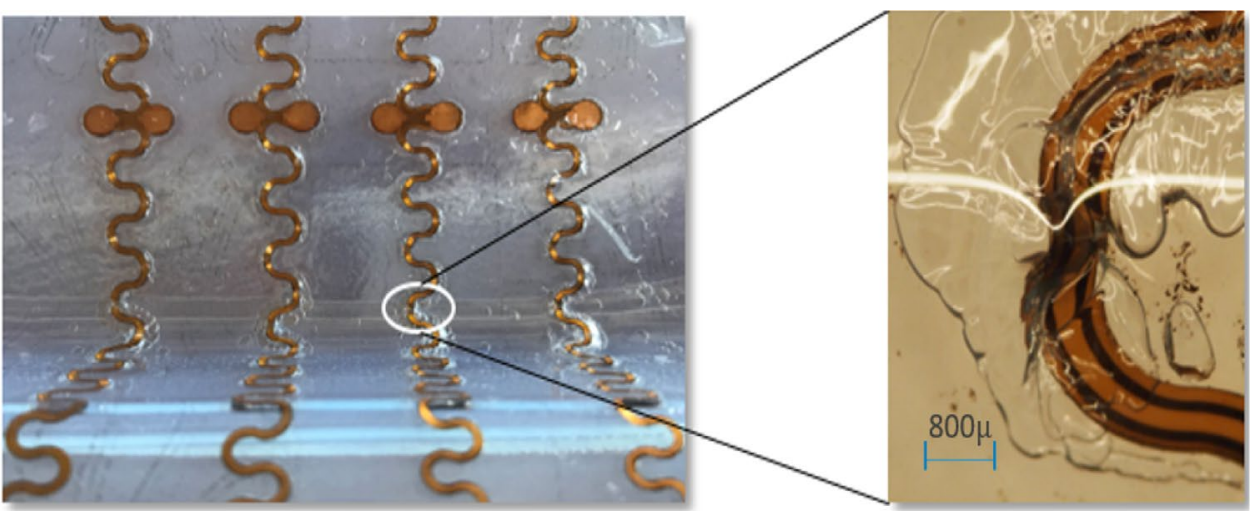




\subsection{Geometry-based approach:}

Because common metal conductors ( $\mathrm{Au}, \mathrm{Cu}, \mathrm{Ni}$, and $\mathrm{Pt}$ ) have very restricted elastic ranges, designing an optimal shape is critical to facilitate conductor stretchability. In [5], several designs of electrical meanders (e.g., elliptical shape, U-shape, and horseshoe shape), were investigated by FEM simulation and experimental tests. Based on simulation results, a horseshoe-shaped meander was found to have the minimum plastic strain distribution after applying 20\% displacement. As a result, this design was found to be the optimal design compared to the elliptical and U-shape. You could find more complex shapes with less out-of-plane deformation, but the horseshoe design is a good compromise between the uniform distribution of stress and out-of-plane deformations along the meander on one hand and ease of interconnect design and lay-outing on the other (a horseshoe meander is composed of circle segments only, which are easy to draw).

A horseshoe-shaped meander consists of a sequence of circular segments with length $\frac{L_{\text {segment }}}{2}=R(\pi+2 \theta)$. Important geometrical parameters for the horseshoe-shaped meander are as follows (Fig. 3):

$L_{\text {segment }}=2 R(\pi+2 \theta)$

The length of the red line in Fig. 3

$H=2 R(1+\sin \theta)$

The total height of the stretchable interconnection

$R=\frac{H}{2(1+\sin \theta)}$

The radius of the meander structure (derived from (2))

$L_{\text {Axial }}=4 R \cos \theta$

The period/pitch of the meander in non-stretched condition.
$\mathrm{E}=\frac{L_{\text {segment }}}{L_{\text {Axial }}}=\left(\frac{2 R(\pi+2 \theta)}{4 R \cos \theta}\right)=\left(\frac{(\pi+2 \theta)}{2 \cos \theta}\right)$

Elongation of the meander, which means the proportion of the final length of the meander after it is fully stretched to the axial length of the meander.

$\mathrm{H}$ is determined by the application: it is the maximum width available in the product design to realize a stretchable interconnection. For a given $\mathrm{H}$, the aim is to find the best $\mathrm{R}$ and $\theta$ maximize $E$ and then add a fractal structure to the horseshoe-shaped meander to maximize the length. As a result of adding fractal structures, we will obtain a higher $E$ because the fractal structure increases the meander length. For different applications, we have predefined values of $w$ (meander width) and $H$, which is a design parameter, limited by the available space. The minimum value for $w$ is the minimum track width which can be realized in the technology of choice, e.g., for PCB (printed circuit board) type technology, the minimum $w$ is in the order of 100 to $150 \mu \mathrm{m}$. Finally, $\mathrm{D}$ is the minimum distance between two adjacent meanders for values of $\theta>0$. D can be calculated as a function of $\mathrm{H}, \theta$, and $\mathrm{w}$ :

$D=H \frac{(2 \cos \theta-1)}{1+\sin \theta}-w$

$\mathrm{D}$ is a continuously decreasing function of $\theta(0<\theta<\pi / 2)$, $\mathrm{D}$ becomes zero for $\theta=\theta_{\max }$.

Elongation $E$ is a continuously increasing function of $\theta$ (Fig. 4). This means that for maximizing $E$ we should maximize $\theta$. However, $\theta$ will be limited to $\theta=\theta_{\max }$. $\mathrm{D}$ cannot be reduced to zero, but should have a minimum value $\mathrm{D}=\mathrm{D}_{\text {min }}$ for at least two reasons: (1) in order to be able to implement the fractal design on the original meander (2) in order to provide sufficient polymer material in between two adjacent meanders to allow extension of this material during the (stretching) thermoforming step (during which D will increase). As will be shown later, the meander width w will to a large extent determine the space needed to add fractal structures to the basic meander.

Fig. 3 Horseshoe-shaped meander's design parameters

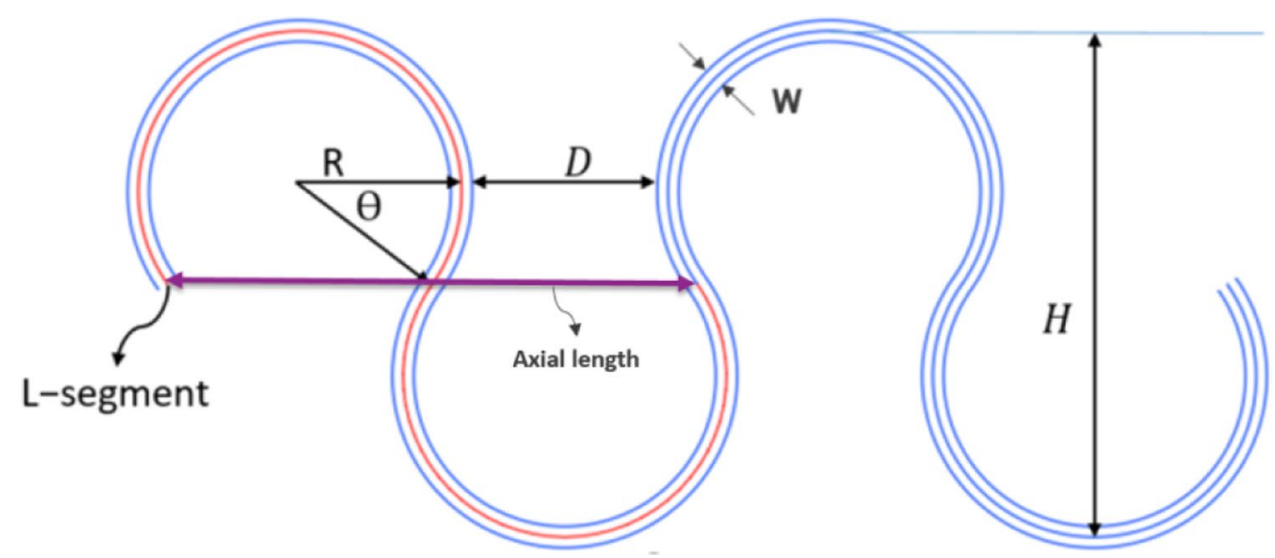



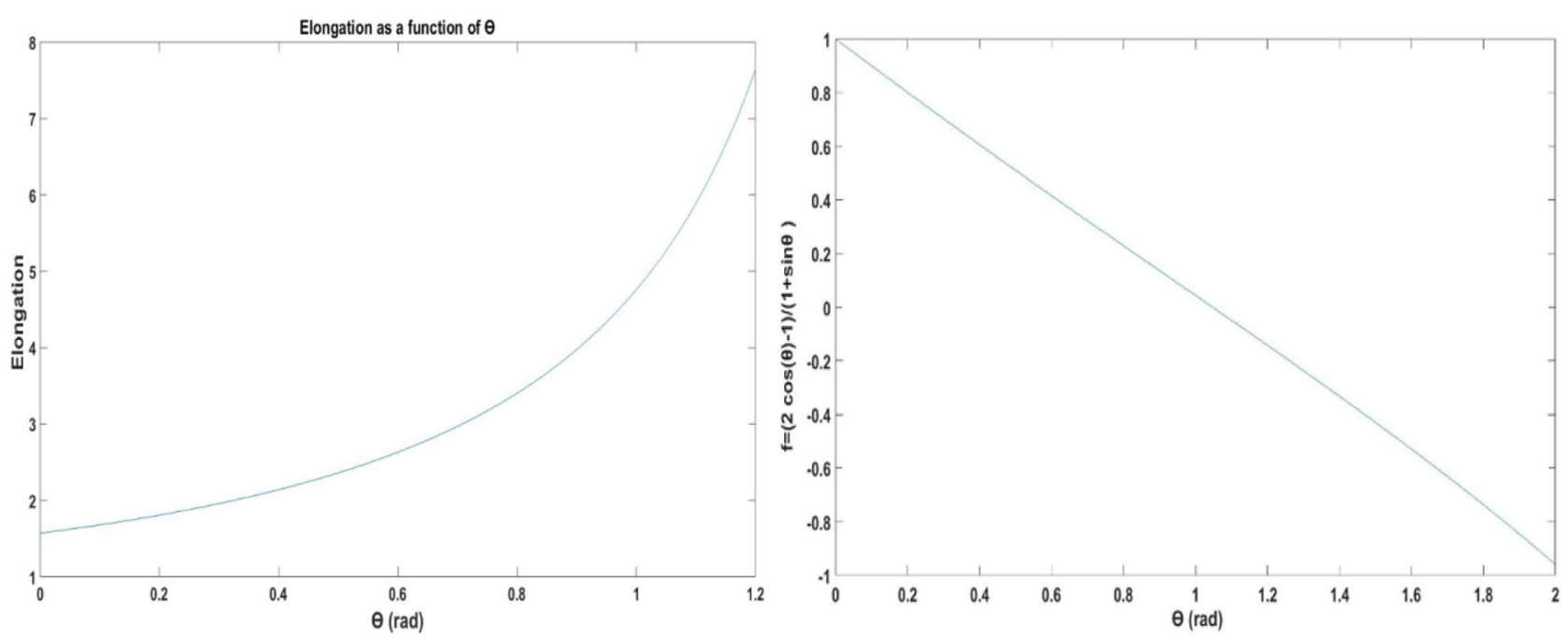

Fig. 4 Elongation $E$ in function of $\theta$ and graphical representation of $\mathrm{f}(\theta)$ in function of $\theta$

$\theta_{\text {Max }}=\sin ^{-1} \frac{-\gamma+\sqrt{\gamma^{2}-4\left(\alpha^{2}-1\right) \beta}}{2 \beta}$

$\gamma=\frac{\alpha w}{H}$

$\beta=1+\left(\frac{w}{2 H}\right)^{2}$

$\alpha=\frac{1}{2}\left(\frac{w}{H}+1\right)$

The distance between the meanders should be at least 3 times the meander width in order to have sufficient space for adding fractal structures. Therefore, we propose the following condition for the lower limit of $\mathrm{D}$ :

$3 w<D$

Combining (6) and (11) leads to the condition:

$f=\frac{(2 \cos \theta-1)}{1+\sin \theta}>\frac{4 w}{H}$

Function $\mathrm{f}(\theta)$ is depicted in Fig. 4. It shows that $\mathrm{f}(\theta)$ is a decreasing function. The maximum allowable $\theta=\theta_{1}$ is calculated from the condition $=\frac{4 w}{H}$. This $\theta_{1}$ yields the maximum achievable elongation (using (12)). Choices for $\theta<\theta_{1}$ will lead to more space for implementing fractal structures, but also to smaller achievable elongation. So the proposed design strategy is the following:

With a given $\mathrm{H}$ (design determined) and $\mathrm{w}$ (technology determined) maximizing the elongation is the goal:

1. Choose the $\max \theta=\theta_{1}$, so that the minimum $\mathrm{D}=3 \mathrm{w}$ is respected
2. With this $\theta$ and with the design-imposed $\mathrm{H}$ : calculate the corresponding $\mathrm{R}$ (using (3)) and maximum achievable elongation (using (5))

After finding $\mathrm{R}$ and $\theta$, thus maximizing the elongation, we need to add the fractal structure to the horseshoe meander. The fractal structure consists of horseshoeshaped meanders, positioned along the original meander, as shown in Fig. 5. The fractal meanders in turn have a fractal radius $R_{f}$ and a fractal angle $\theta_{f}$, along to the original large meander.

We need to determine $R_{f}$ and $\theta_{f}$ of fractal meanders that maximize $E_{f}$ of the fractal meander structure (Fig. 6).

$E_{f}=\frac{L_{\text {segment }-f}}{L_{\text {Axial }-f}}=\frac{\left(\pi+2 \theta_{f}\right)}{2 \cos \theta_{f}}$

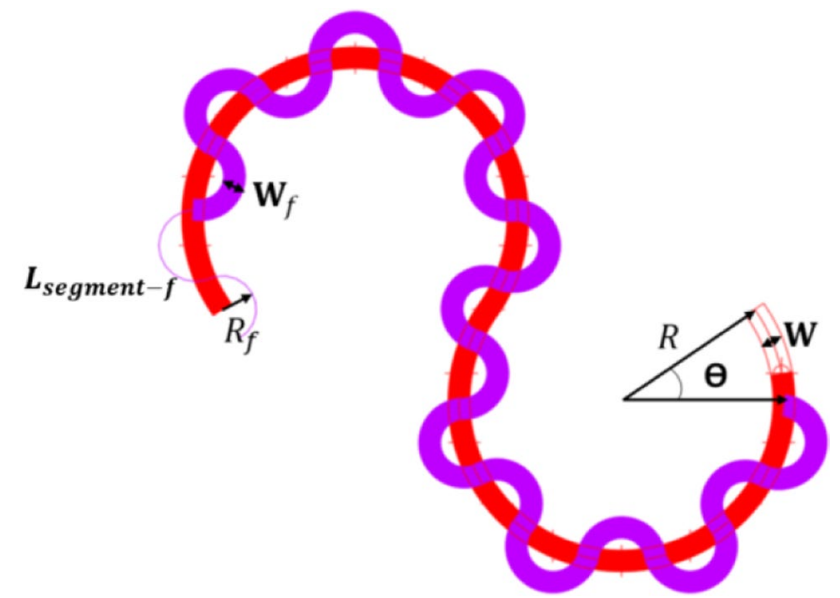

Fig. 5 Fractal structure added to the original meander and fractal design parameters 


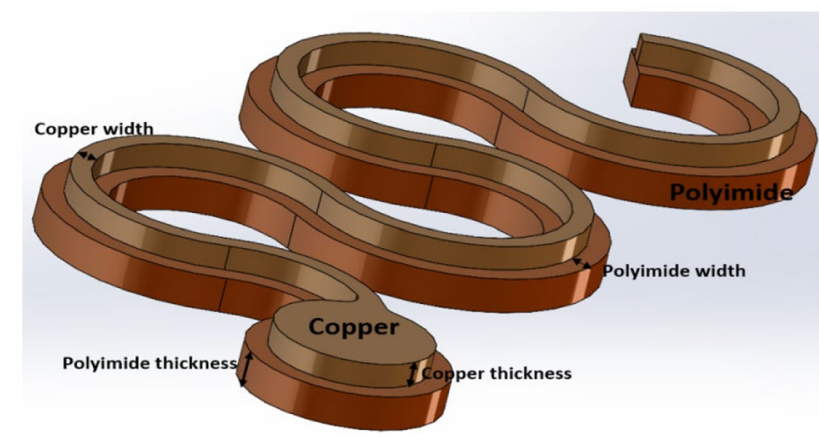

Fig. 6 Design parameters: copper width, copper thickness, polyimide width, polyimide, polyimide thickness

$R_{f}=\frac{L_{\text {segment }}}{2 m \cos \theta_{f}}$

$E_{f}$ is a strictly increasing function and the larger $\theta_{f}$, the larger $E_{f}$. When it comes to designing the fractal structure, it becomes hard and time-consuming to design this in CAD if we choose a value larger than 0 for $\theta_{f}$ and there is no substantial gain in $E_{f}$ by increasing $\theta_{f}$. So, we choose $\theta_{f}=0$.

$E_{f}=\frac{L_{\text {segment }-f}}{L_{\text {Axial }-f}}=\frac{\pi}{2}=1.57$

$R_{f}=\frac{L_{\text {segment }}}{2 m \cos \theta_{f}}=\frac{L_{\text {segment }}}{2 m}$

Based on (16), we can increase the length of the original meander by $57 \%$ by adding the fractal structure. We have a design process that we use in CAD to add fractal structure to the basic meander, and it works as follows:

1. Divide $L_{\text {Segment }}$ into m equal parts, we call the length of each equal part $\mathrm{L}$.

2. Draw a half circuit around each segment (each equal component) as shown in Fig. 6.

3. The fractal meander's radius is equal to $L / 2$.

We introduce the following boundary condition for choosing $\mathrm{m}$ :

$2 R_{f}>4 w$

\subsection{Fabrication-based approach}

Geometry has an essential role in buckling deformation, but the conductor thickness and width and polyimide thickness and width also play an important role. These parameters are depicted in Fig. 6. In this paper, we have used Upisel copper-polyimide-based laminates as flexible substrates. The copper width is a design-based parameter and we are restricted to change it. But we can tune other parameters, i.e., polyimide and $\mathrm{Cu}$ thickness to minimize the stress in the circuit. Four different combinations of polyimide and $\mathrm{Cu}$ thicknesses are commercially available (Table 1).

Based on [Yung-Yu Hsu], the polyimide's width, which is symmetrical on both sides of the $\mathrm{Cu}$, can affect the meander's stress distribution. Our simulation investigated the copper thickness, polyimide thickness, and polyimide width on the stress distribution and out-of-plane buckling. To simulate stretching in a thermoformed sample, we have involved the thermal expansion of the materials in the finite element simulation. Table 2 represents the simulation results. Based on Table 2, the best fabrication stack for having minimum stress is stack number 7: polyimide thickness $=50 \mu \mathrm{m}$, polyimide width $=100 \mu \mathrm{m}$, which is the additional width compared to the copper and copper thickness $=35 \mu \mathrm{m}$.

\section{Simulations and results}

A fractal meander will be designed for a specific application, and the simulation results of three different meander shapes will be discussed and compared.

\subsection{Case study definition}

We need a case study to verify our approach. This test design aims to design three parallel tracks in a meander shape to power and measure a touch sensor. In the $3 \mathrm{D}$ shape design, there is cavity between powering pads and the sensor depicted in Fig. 7. The initial length of the meander is $L_{1}=60 \mathrm{~mm}$ and the length of the stretched meander after thermoforming will be $L_{2}=78 \mathrm{~mm}$. So, we need to design a meander that can accommodate this amount of stretching. Based on [5], there will be less stress on the crest regions when multiple copper lines are used instead of using a single-track meander design. In the following example, we've investigated the worst-case scenario, and we have used a single-track meander design with a width of $0.85 \mathrm{~mm}$. The following parameters are defined in this design:

Table 1 Different combinations of polyimide and $\mathrm{Cu}$ thicknesses

\begin{tabular}{lll}
\hline Thickness & Copper thickness & Polyimide thickness \\
\hline Stack-1 & $18 \mu \mathrm{m}$ & $50 \mu \mathrm{m}$ \\
Stack-1 & $35 \mu \mathrm{m}$ & $50 \mu \mathrm{m}$ \\
Stack-1 & $18 \mu \mathrm{m}$ & $25 \mu \mathrm{m}$ \\
Stack-1 & $35 \mu \mathrm{m}$ & $25 \mu \mathrm{m}$ \\
\hline
\end{tabular}


Table 2 Different fabrication stacks for the meander structures

\begin{tabular}{llllll}
\hline Stack & Copper width & Copper thickness & $\begin{array}{l}\text { Polyimide } \\
\text { thickness }\end{array}$ & Polyimide width & von Mises stress \\
\hline 1 & $0.85 \mathrm{~mm}$ & $18 \mu \mathrm{m}$ & $50 \mu \mathrm{m}$ & $0 \mu \mathrm{m}$ & $3.9 \times 10^{9} \frac{\mathrm{N}}{\mathrm{m}^{2}}$ \\
2 & $0.85 \mathrm{~mm}$ & $18 \mu \mathrm{m}$ & $25 \mu \mathrm{m}$ & $0 \mu \mathrm{m}$ & $3.94 \times 10^{9} \frac{\mathrm{N}}{\mathrm{m}^{2}}$ \\
3 & $0.85 \mathrm{~mm}$ & $35 \mu \mathrm{m}$ & $50 \mu \mathrm{m}$ & $0 \mu \mathrm{m}$ & $2.81 \times 10^{9} \frac{\mathrm{N}}{\mathrm{m}^{2}}$ \\
4 & $0.85 \mathrm{~mm}$ & $35 \mu \mathrm{m}$ & $25 \mu \mathrm{m}$ & $0 \mu \mathrm{m}$ & $3.33 \times 10^{9} \frac{\mathrm{N}}{\mathrm{m}^{2}}$ \\
5 & $0.85 \mathrm{~mm}$ & $18 \mu \mathrm{m}$ & $50 \mu \mathrm{m}$ & $100 \mu \mathrm{m}$ & $4.16 \times 10^{9} \frac{\mathrm{N}}{\mathrm{m}^{2}}$ \\
6 & $0.85 \mathrm{~mm}$ & $18 \mu \mathrm{m}$ & $25 \mu \mathrm{m}$ & $100 \mu \mathrm{m}$ & $4 \times 10^{9} \frac{\mathrm{N}}{\mathrm{m}^{2}}$ \\
$\mathbf{7}$ & $0.85 \mathrm{~mm}$ & $\mathbf{3 5 \mu \mathrm { m }}$ & $\mathbf{5 0 \mu \mathrm { m }}$ & $\mathbf{1 0 0 \mu \mathrm { m }}$ & $2.52 \times 10^{9} \frac{\mathrm{N}}{\mathrm{m}^{2}}$ \\
8 & $0.85 \mathrm{~mm}$ & $35 \mu \mathrm{m}$ & $25 \mu \mathrm{m}$ & $100 \mu \mathrm{m}$ & $2.68 \times 10^{9} \frac{\mathrm{N}}{\mathrm{m}^{2}}$ \\
9 & $0.85 \mathrm{~mm}$ & $18 \mu \mathrm{m}$ & $50 \mu \mathrm{m}$ & $200 \mu \mathrm{m}$ & $3.96 \times 10^{9} \frac{\mathrm{N}}{\mathrm{m}^{2}}$ \\
10 & $0.85 \mathrm{~mm}$ & $18 \mu \mathrm{m}$ & $25 \mu \mathrm{m}$ & $200 \mu \mathrm{m}$ & $3.82 \times 10^{9} \frac{\mathrm{N}}{\mathrm{m}^{2}}$ \\
11 & $0.85 \mathrm{~mm}$ & $35 \mu \mathrm{m}$ & $50 \mu \mathrm{m}$ & $200 \mu \mathrm{m}$ & $2.71 \times 10^{9} \frac{\mathrm{N}}{\mathrm{m}^{2}}$ \\
12 & $0.85 \mathrm{~mm}$ & $35 \mu \mathrm{m}$ & $25 \mu \mathrm{m}$ & $200 \mu \mathrm{m}$ & $2.84 \times 10^{9} \frac{\mathrm{N}}{\mathrm{m}^{2}}$ \\
\hline
\end{tabular}

$\mathrm{H}=20 \mathrm{~mm}$, copper width $=0.85 \mathrm{~mm}$, polyimide

$\frac{(2 \cos \theta-1)}{1+\sin \theta}=0.17$

Meander's elongation $=\frac{L_{2}-L_{1}}{L_{1}}=\frac{(78-60) \mathrm{mm}}{60 \mathrm{~mm}}=30 \%$

The goal is to maximize $E$, which means:

$H=2 R(1+\sin \theta)=20 \mathrm{~mm}$

$$
\max (E)
$$

First, we need to solve Eq. (12) to calculate the corresponding $\theta$ :

$f=\frac{(2 \cos \theta-1)}{1+\sin \theta}>\frac{4(0.85)}{20}=0.17$

Instead of solving (12), we solve the following equation to calculate $\theta_{1}$, which is the point that $f=0.17$ and $\theta_{1}=0.86$.
Based on the explanation in the previous section, we choose $\theta=0.85$ to fulfill (12) and maximize. By substituting $\theta=0.85$ in Eq. (3), we calculate $R=5.58$. For adding the fractal design to the original meander, we selected $\theta_{f}=0, m=20$ (Fig. 10). $R_{f}$ can be calculated as follows:

$R_{f}=\frac{R(\pi+2 \theta)}{m}=1.35 \mathrm{~mm}$

By adding the fractal structure, the length of the original meander is increased by 57 percent fractal. This length increase is higher than the 30 percent elongation that is needed in this application. Therefore, we don't expect to have out-of-plane buckling after thermoforming.

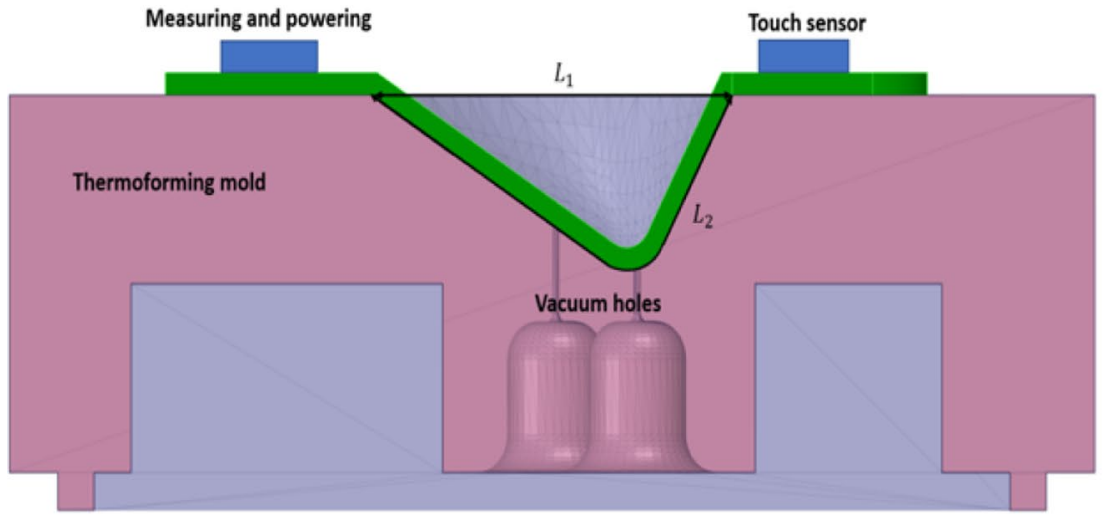

a

Fig. 7 (a) 3D circuit to be fabricated: (a) cross-sectional view of the thermoforming mold, the touch sensor's position, and the measuring and powering part's position. The green material is the thermoformed

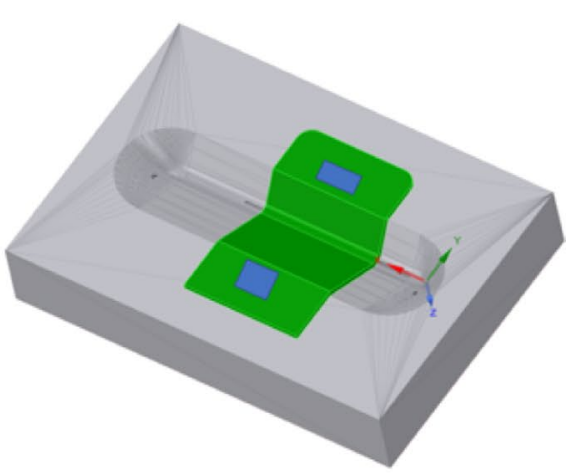

b stack. (b) Perspective view of the thermoforming mold and thermoformed stack. 


\subsection{Simulation}

Simulation results also verify our analytical approach. We applied 30 percent displacement in the simulation. We used COMSOL multiphysics software for finite element simulation. In the simulation, we coupled solid mechanics and heat transfer in solids, simulating the thermal expansion of the copper and polyimide layer and the displacement at a specific temperature. We've chosen $170^{\circ} \mathrm{C}$ as this is the temperature at which the thermoforming step is done. Figure 8 represents the CAD design of the various patterns used in the simulation for comparison. We compared the von Mises stress of the original meander (e.g., horseshoe) with the fractal design and the particular pattern presented in [10], a combination of a triangular and horseshoe shape (Fig. 9). Furthermore, we have simulated linear buckling, which indicates the surface displacement of the meander under applied displacement; this simulation directly shows the out-of-plane deformation for each meander (Fig. 10). Table 3 represents the different meander types' axial length and design parameters and Table 4 represents the material properties which have been used in the simulation. Based on the simulation (Figs. 9 and 10), the minimum von Mises stress and the minimum surface displacement is for the fractal pattern, which means having less out-of-plane deformation [5, 12]

\section{Experimental results}

The different stages of fabricating and thermoforming the designed meander will be explained in detail.

\subsection{Fabrication}

The copper pattern is designed in AutoCAD, realized using lithography and wet etching of Upisel SR1220 (50 $\mu \mathrm{m}$ PI-18 $\mu \mathrm{m}$ RA Cu$)$. For mechanical stability of the structure, an FR-4 substrate with a Tacsil tape, which is comprised of FR-4 substrate and double side tape on top, is used to hold the structure during laser cutting and lamination. The etched pattern is lasered using specific parameters for the laser setup, and the structured copper pattern is peeled off from the Tacsil tape (Fig. 11).

\subsection{Lamination}

First, we dehydrate the $\mathrm{PC}$ in an oven at $120^{\circ} \mathrm{C}$ for $1 \mathrm{~h}$. We use an A4 layer of Lexan $250 \mu \mathrm{m}$ polycarbonate and TPU Bemis $100 \mu \mathrm{m}$ to be laminated with each other. TPU is applied to the PC by using a roller to remove bubbles. We use a Lauffer $\mathrm{XYZ}$ press laminator machine to laminate $\mathrm{PC}$ and TPU with each other. We produce two PC-TPU laminated stacks and we use one of them to be laminated on top of the stack in step (3). We peel off the laminated stack from the carrier board; we use the second PC_TPU to be laminated to the peeled-off stack to make a symmetrically laminated stack (Fig. 12). We used a specific profile for temperature and pressure during the lamination process (Fig. 13). We can see the lamination result in Fig. 14.

\subsection{Thermoforming}

Figure 15 shows the used thermoforming process: aligning a fabricated stack in the thermoforming machine and heating
Fig. 8 The original meander design and the fractal version of the original meander
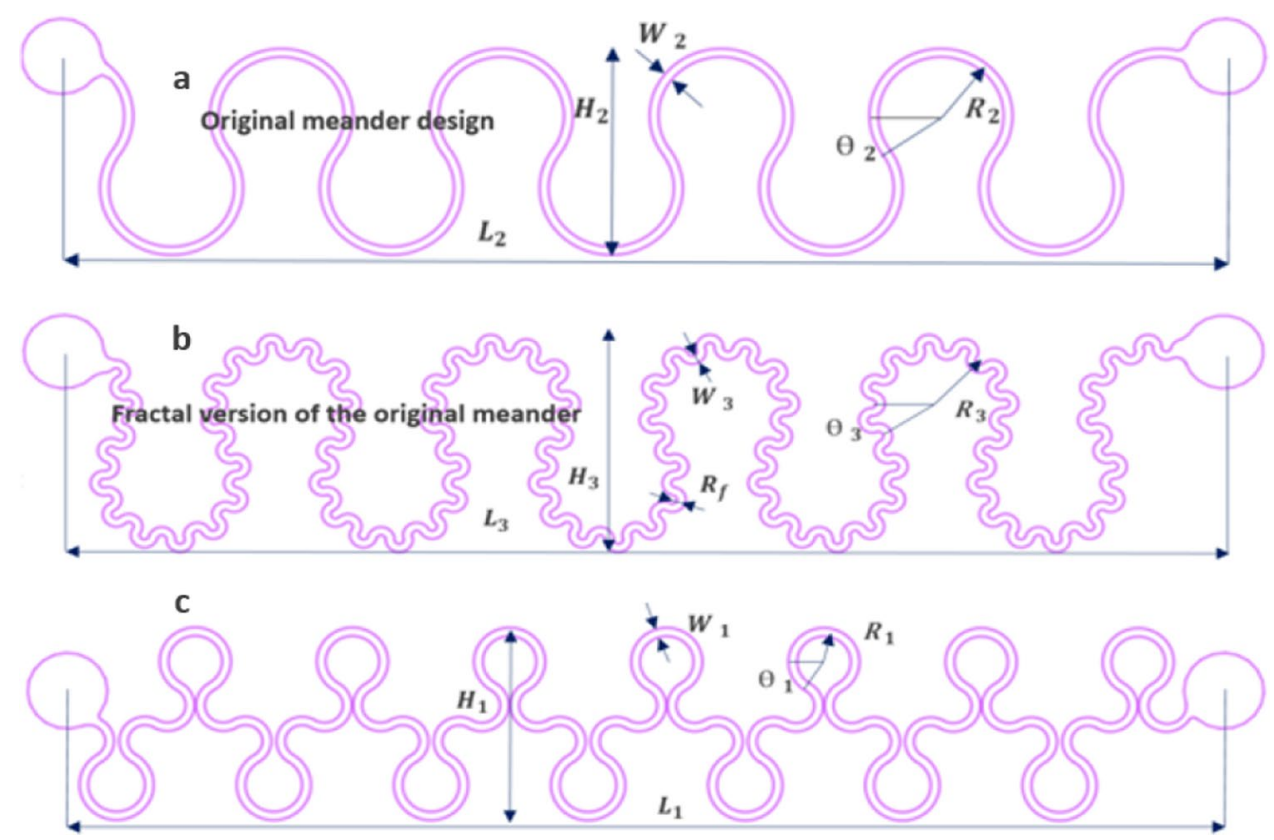


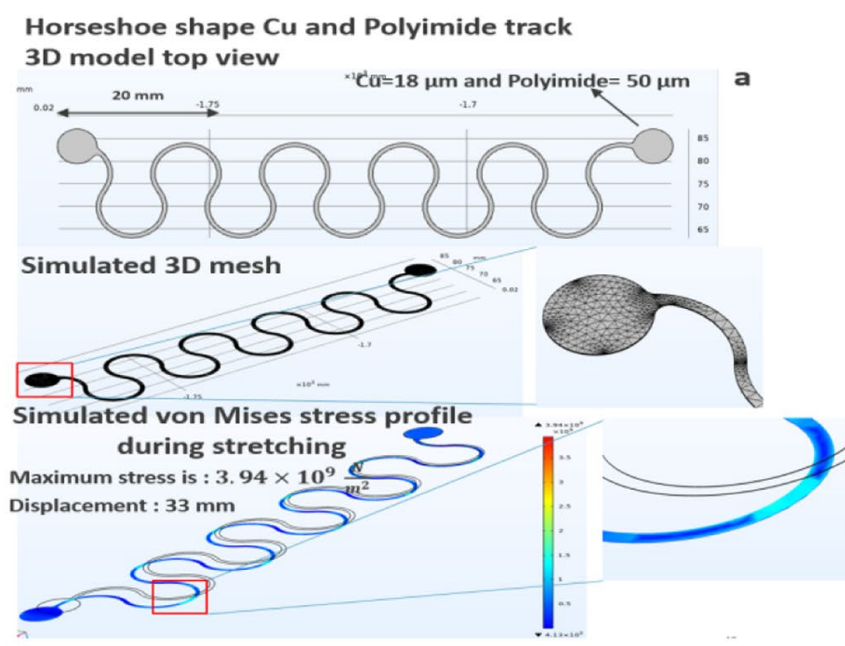

Fractional shape $\mathrm{Cu}$ and polyimide track

3D model top view

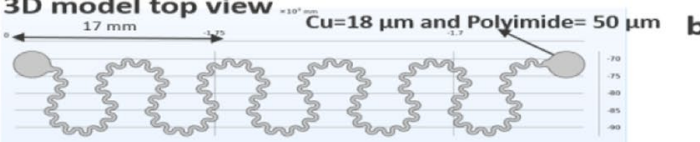

Simulated 3D mesh

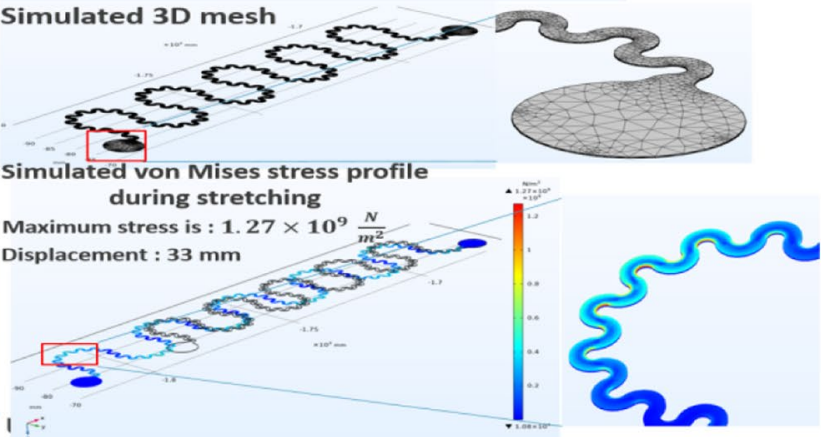

Combination shape $\mathrm{Cu}$ and Polyimide track 3D model top view

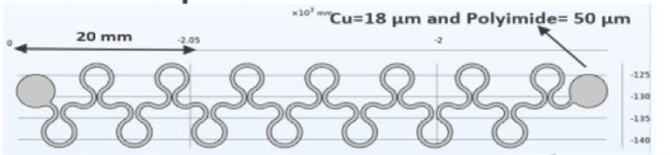

C

Simulated 3D mesh
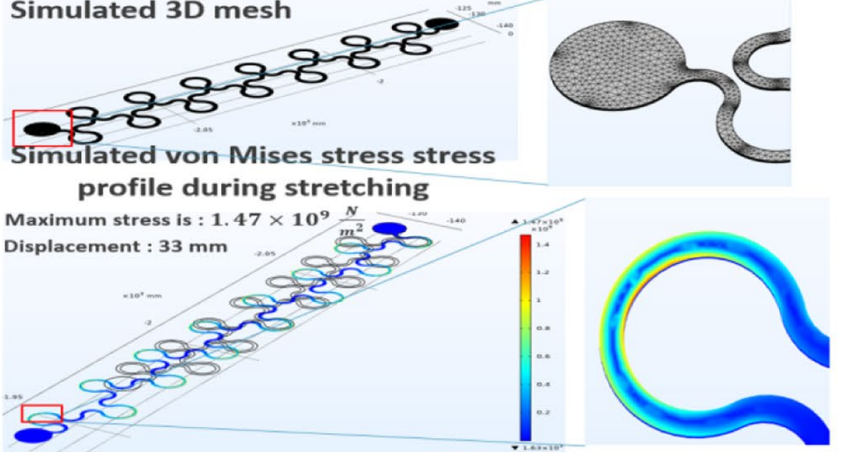

Fig. 9 The simulation results in COMSOL multiphysics: (a) Indicating the maximum stress related to Horseshoe-shaped meander, the highest among others. (b) Demonstrating the maximum stress related to fractal-shaped meander, the lowest among others. (c) Representing the maximum stress related to combination-shaped meander

moment that the polymer touches the cold mold, it starts to solidify and the material becomes solid (d). The 70 percent elongation mold design can be seen in Fig. 15e and the 30 percent elongation mold design can be seen in Fig. 15f.
Table 3 The different meander types and their axial length and design parameters

\begin{tabular}{|c|c|c|c|}
\hline Meander type & Path length & Axial length & Meander parameter \\
\hline Combination & $P_{1}=409 \mathrm{~mm}$ & $L_{1}=101.4 \mathrm{~mm}$ & $H_{1}=20 \mathrm{~mm}, W_{1}=0.85, \theta_{1}=60^{\circ}, \mathrm{R}_{1}=3 \mathrm{~mm}$ \\
\hline Horseshoe & $P_{2}=277 \mathrm{~mm}$ & $L_{1}=101.4 \mathrm{~mm}$ & $H_{2}=20 \mathrm{~mm}, W_{2}=0.85, \theta_{2}=35^{\circ}, \mathrm{R}_{2}=6.42 \mathrm{~mm}$ \\
\hline Fractal & $P_{3}=436 \mathrm{~mm}$ & $L_{1}=101.4 \mathrm{~mm}$ & $\begin{array}{l}H_{3}=20 m m, W_{3}=0.85, \theta_{3}=35^{\circ}, \mathrm{R}_{3}=5.58 \\
\quad \mathrm{~mm}, \mathrm{R}_{f}=1.35 \mathrm{~mm}\end{array}$ \\
\hline
\end{tabular}


Table 4 Material properties

\begin{tabular}{llll}
\hline Polyimide & Value & Copper & Value \\
\hline Young's modulus & $3.1 \mathrm{e} 9[\mathrm{~Pa}]$ & Young's modulus & $110 \mathrm{e} 9[\mathrm{~Pa}]$ \\
Poisson's ratio & 0.34 & Poisson's ratio & 0.35 \\
$\begin{array}{c}\text { Coefficient of ther- } \\
\text { mal expansion }\end{array}$ & $9 \mathrm{e}-6[1 / \mathrm{K}]$ & $\begin{array}{c}\text { Coefficient of ther- } \\
\text { mal expansion }\end{array}$ & $17 \mathrm{e}-6[1 / \mathrm{K}]$ \\
\hline
\end{tabular}

\section{Results and discussion}

A qualitative and quantitative comparison between simulation and experimental results will be discussed and the results of the current paper will be compared with previous work.

\subsection{Qualitative comparison}

The basic idea behind adding the fractal structures to the original meander shape is to increase the meander's path length. Based on our simulations, we have shown that the larger the meander path length is, the smaller is the maximum stress and strain, and surface displacement on the crest region of the meanders; as a result, there will be less out-of-plane deformation (Table 5). By adding the fractal structure, the fractal meander shape has the longest length, consequently the minimum stress along the meander. Visual inspection of the experimental results confirms the simulation results and shows that the minimum outof-plane deformation occurs for the fractal meander shape (Fig. 16). Furthermore, measured out-of-plane deformation confirms that the fractal design has the minimum outof-plane deformation (in the order of $200 \mu \mathrm{m}$ ) (Fig. 17).

\subsection{Quantitative comparison}

We have found a way to measure the specific values of the out-of-plane deformations in the samples. It consists of cutting the top part of the semi-sphere thermoformed samples, fixing the sample with epoxy resin, and finally polishing in order that the out-of-plane deformed conductor track is at the surface of the cross-sectioned sample (Fig. 17):

Cross section samples provide the following view for inspection by microscope (Fig. 18). By using an optical microscope, we have measured the value of out-of-plane deformation for different designs (Fig. 19).

\subsection{Simulation verification}

A qualitative comparison between FEM and experiments shows that calculated regions with a high concentration of

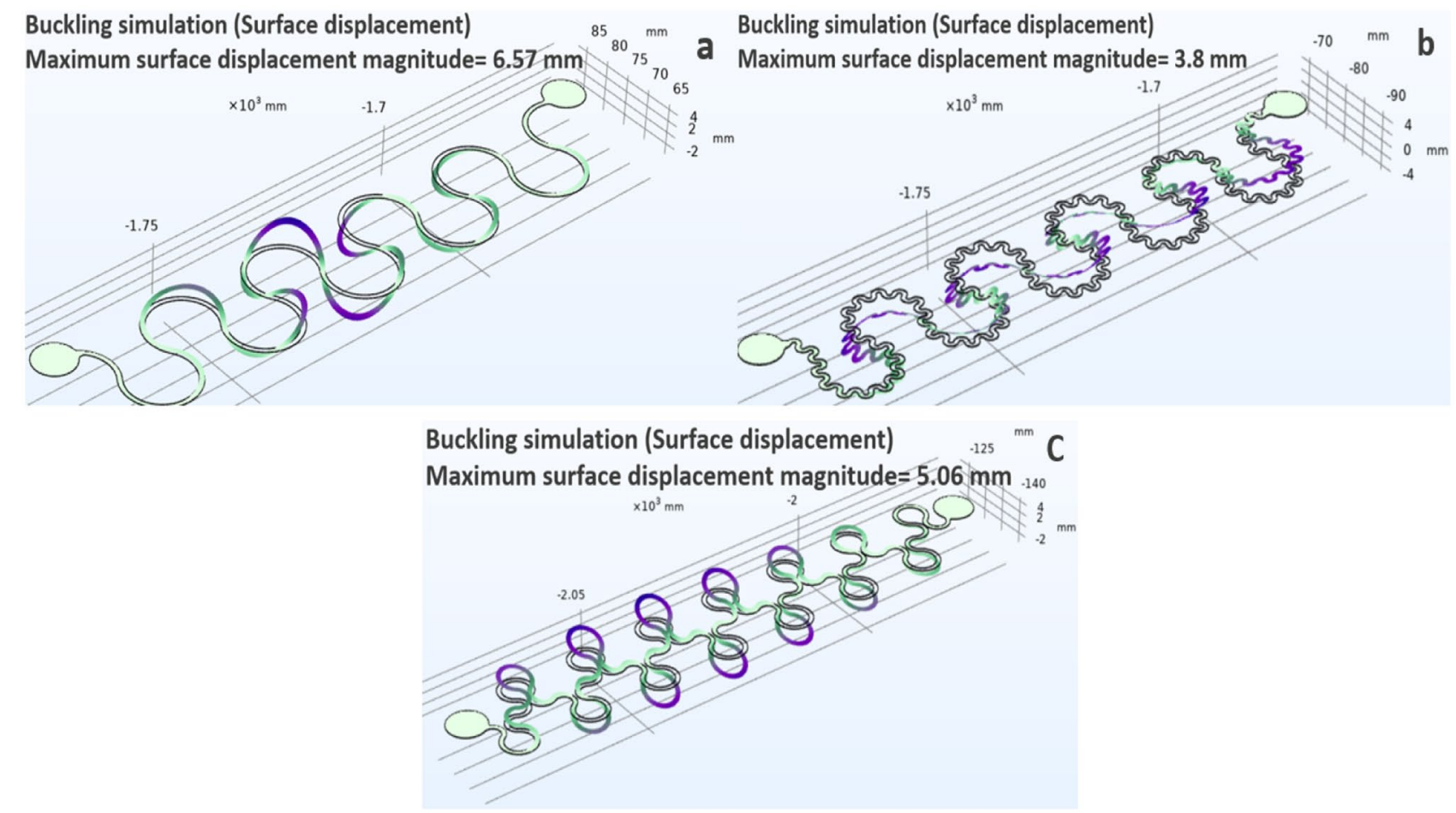

Fig. 10 Linear buckling simulation, which shows surface displacement. (a) Representing the maximum surface displacement related to Horseshoe-shaped meander, the highest among others. (b) Indicating the maximum surface displacement related to fractal-shaped meander, the lowest among others. (c) Representing the maximum surface displacement related to combination-shaped meander 
Fig. 11 Different steps of fabrication process of the meander structure on the copper and polyimide substrate. (Step 1) $\mathrm{Cu}$ patterning and etching. (Step

2) Lamination of $\mathrm{PI} / \mathrm{Cu}$ flex circuit on carrier board. (Step 3) Laser ablation and removal of excess PI. (Step 4) Removal of PI supported $\mathrm{Cu}$ meander from carrier board

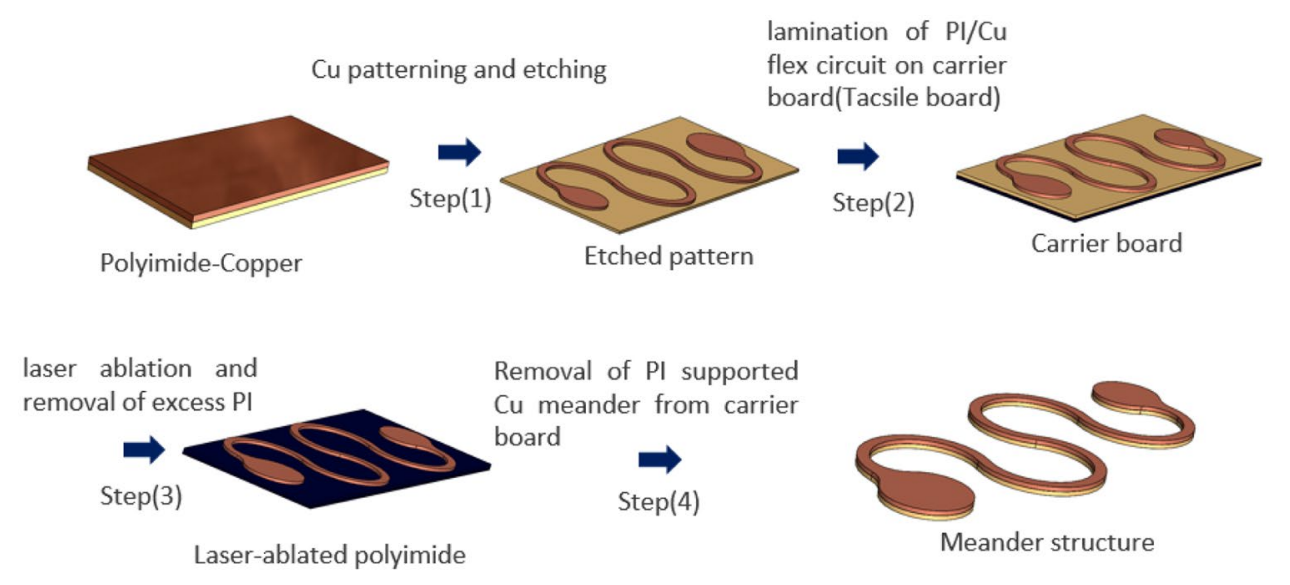

\section{a}

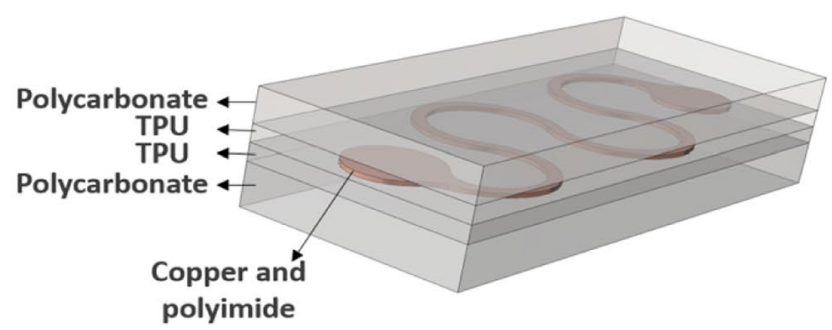

b

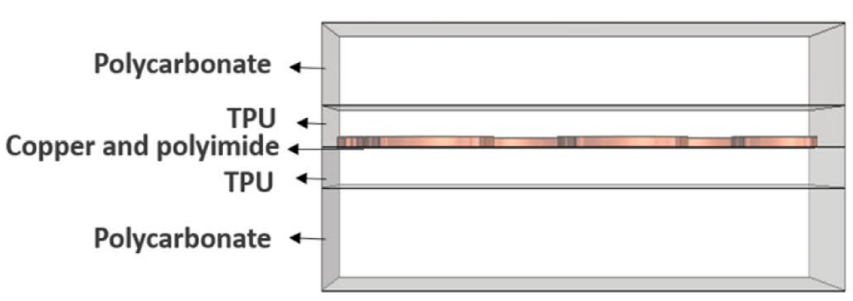

Fig. 12 The lamination stack, which is comprised of polycarbonate, TPU, Cu, polyimide

Fig. 13 Profile for temperature and pressure during the lamination process

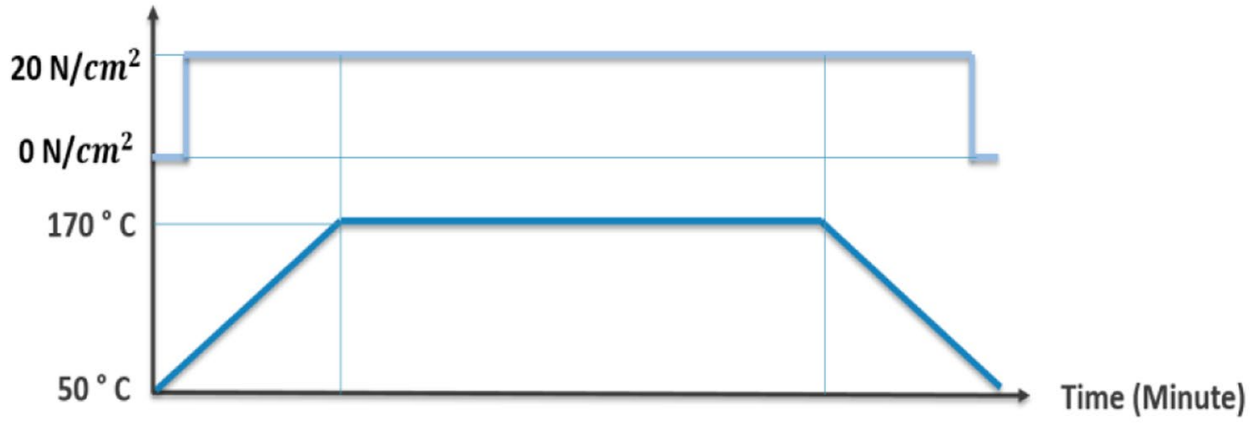

Table 5 The different meander shapes and their maximum stress, strain, and surface displacement

\begin{tabular}{llllll}
\hline Meander type & Path length & Von Mises stress Maximum & $\begin{array}{l}\text { Maximum first principal } \\
\text { stress }\end{array}$ & Maximum strain & $\begin{array}{l}\text { Maximum surface } \\
\text { displacement }\end{array}$ \\
\hline Combination & $P_{1}=409 \mathrm{~mm}$ & $1.47 \times 10^{9} \frac{\mathrm{N}}{\mathrm{m}^{2}}$ & $1.49 \times 10^{9} \frac{\mathrm{N}}{\mathrm{m}^{2}}$ & 0.013451 & $5.6 \mathrm{~mm}$ \\
Horseshoe & $P_{2}=277 \mathrm{~mm}$ & $3.94 \times 10^{9} \frac{\mathrm{N}}{\mathrm{m}^{2}}$ & $3.43 \times 10^{9} \frac{\mathrm{N}}{\mathrm{m}^{2}}$ & 0.038171 & $6.57 \mathrm{~mm}$ \\
Fractal & $P_{3}=436 \mathrm{~mm}$ & $1.27 \times 10^{9} \frac{\mathrm{N}}{\mathrm{m}^{2}}$ & $1.33 \times 10^{9} \frac{\mathrm{N}}{\mathrm{m}^{2}}$ & 0.011716 & $3.8 \mathrm{~mm}$ \\
\hline
\end{tabular}


Fig. 14 The thermoformable stack after lamination of the meander between two symmetric layers of polycarbonate and TPU

Fig. 15 Thermoforming machine heats a laminated stack until it reaches its glass transition temperature and becomes soft. After that, it is formed using a mold and a strong vacuum. Typically, forming consists of the following steps: (a) Clamping and aligning the sheet; (b) Heating the sheet beyond its glass transition temperature; (c) Elevating the mold toward the thermoplastic sheet and using a vacuum to remove all the air between the sheet and mold and cooling the formed material. (d) Final thermoformed object. (e) 70 percent elongation mold. (f) $30 \%$ elongation mold

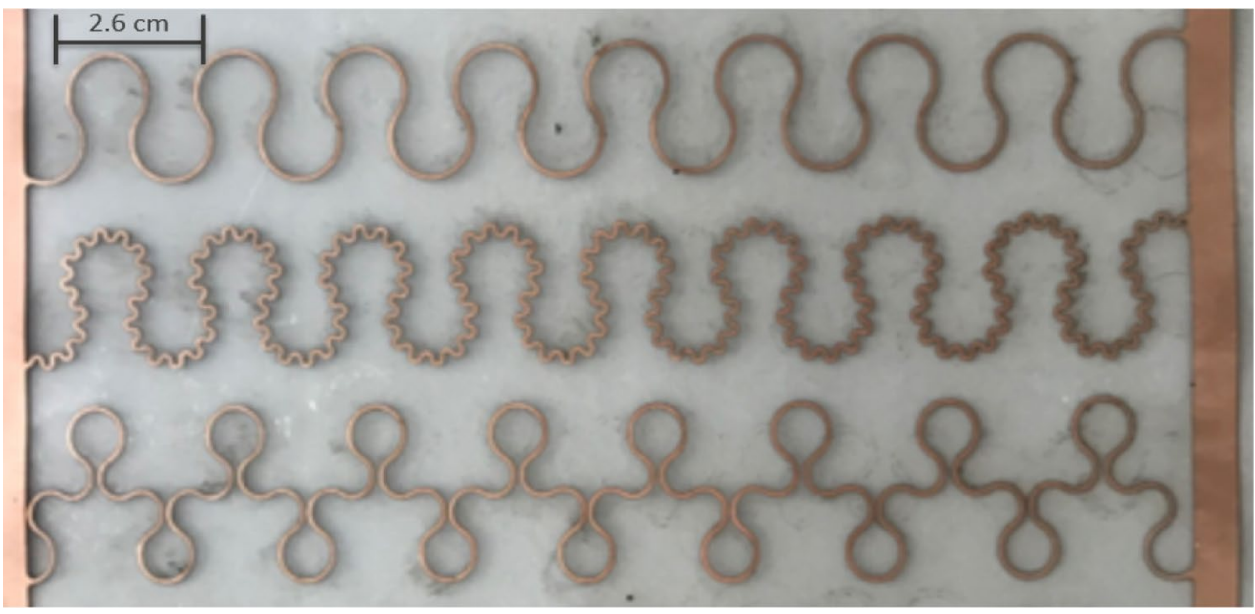

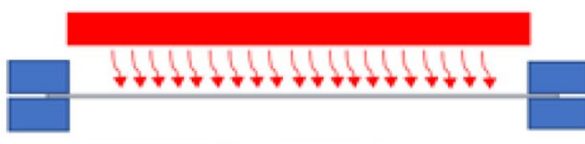

a

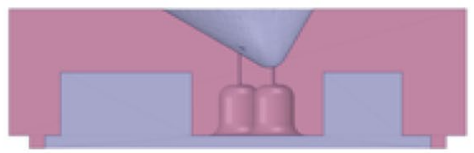

c

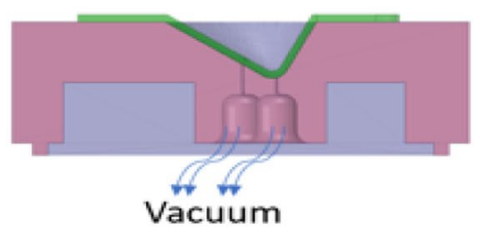

70 percent elongation mold

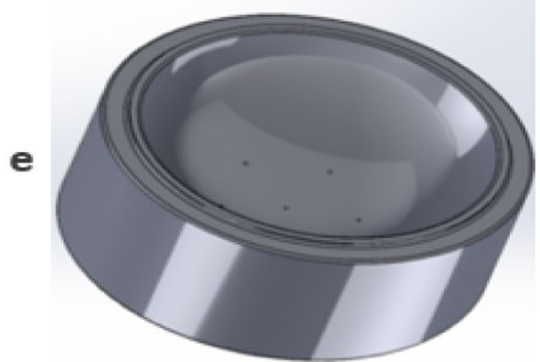

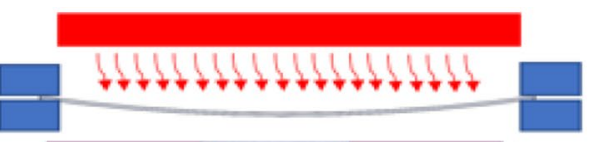

b
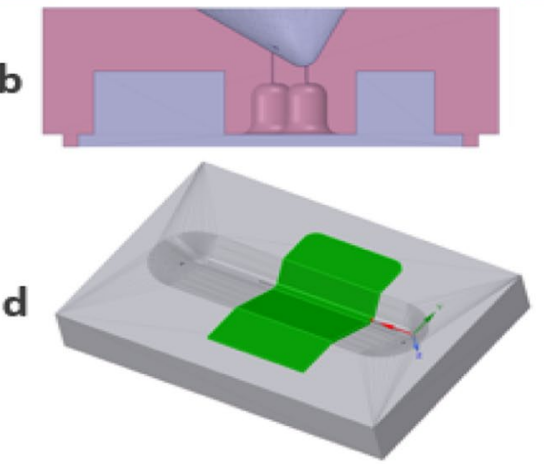

30 percent elongation mold

f

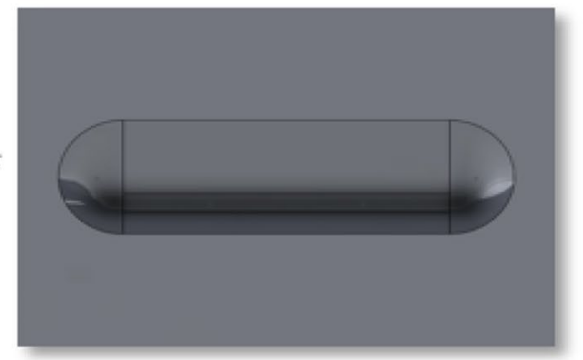



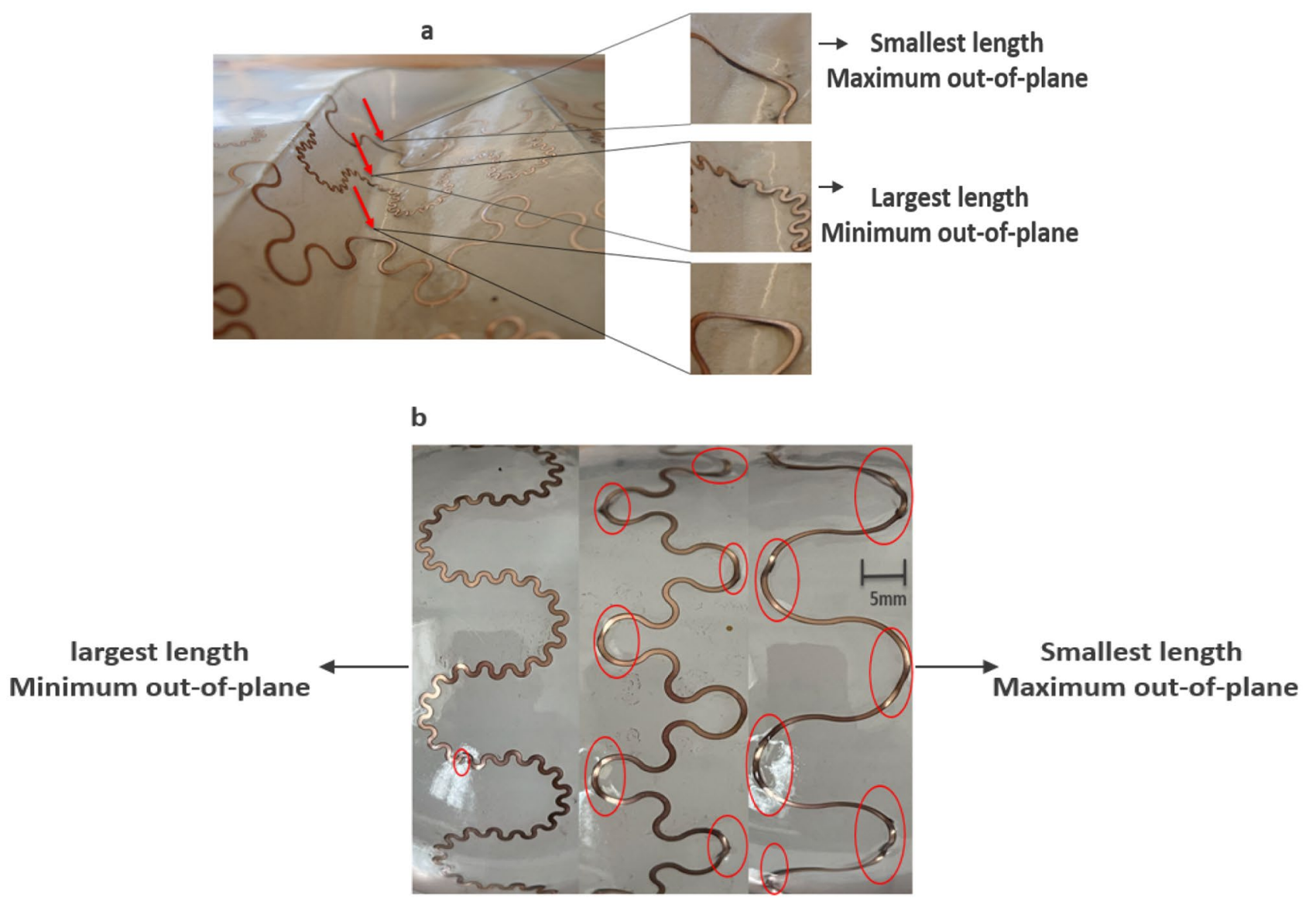

Fig. 16 Thermoformed samples: (a) Thermoformed sample with 30\% elongation mold. (b) Thermoformed sample with 70\% elongation mold

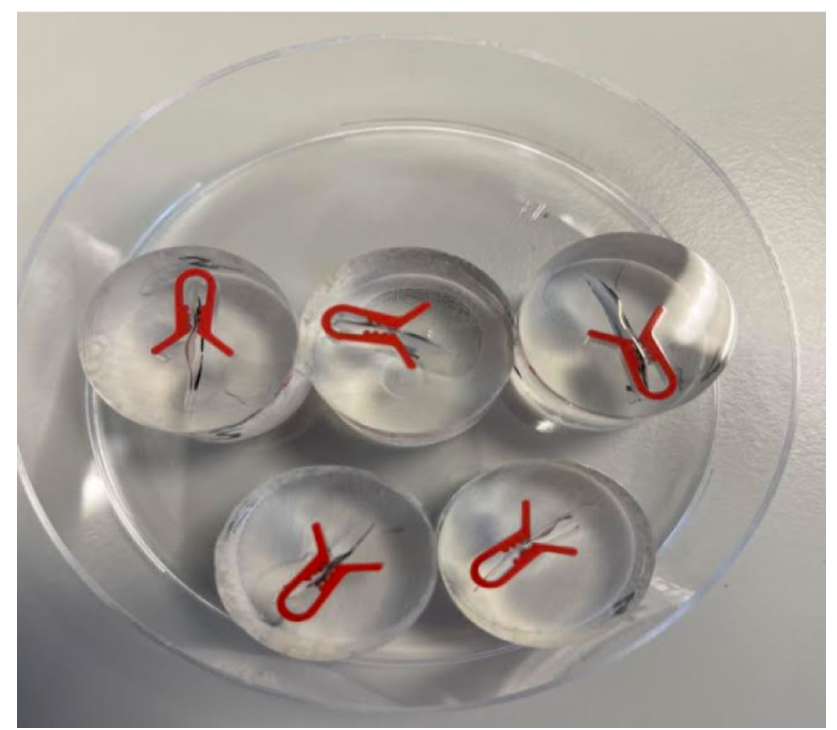

Fig. 17 Samples for cross-sectional investigation. A cut-out part of a thermoformed circuit is clamped (clamps are the red colored parts in the picture). (Transparent) epoxy is casted over the clamped samples, After curing/hardening of the epoxy, the samples are grinded and polished until the desired out-of-plane deformed interconnection track appears at the surface. This surface is then inspected with an optical microscope

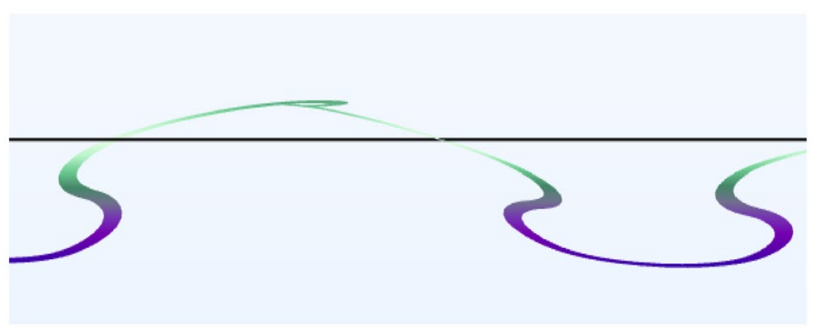

Fig. 18 The view provided by cross-sectioned samples

Table 6 The different meander shapes and their maximum stress, strain, and surface displacement

\begin{tabular}{llll}
\hline & Horseshoe & Fractal & Combination \\
\hline $\begin{array}{l}\text { Linear buckling simulation } \\
\text { (surface displacement) }\end{array}$ & $6.57 \mathrm{~mm}$ & $3.8 \mathrm{~mm}$ & $5.06 \mathrm{~mm}$ \\
$\begin{array}{l}\text { Measured displacement } \\
\text { by microscope (Rounded } \\
\text { values) }\end{array}$ & $1200 \mathrm{um}$ & $140 \mathrm{um}$ & $700 \mathrm{~mm}$ \\
\hline
\end{tabular}



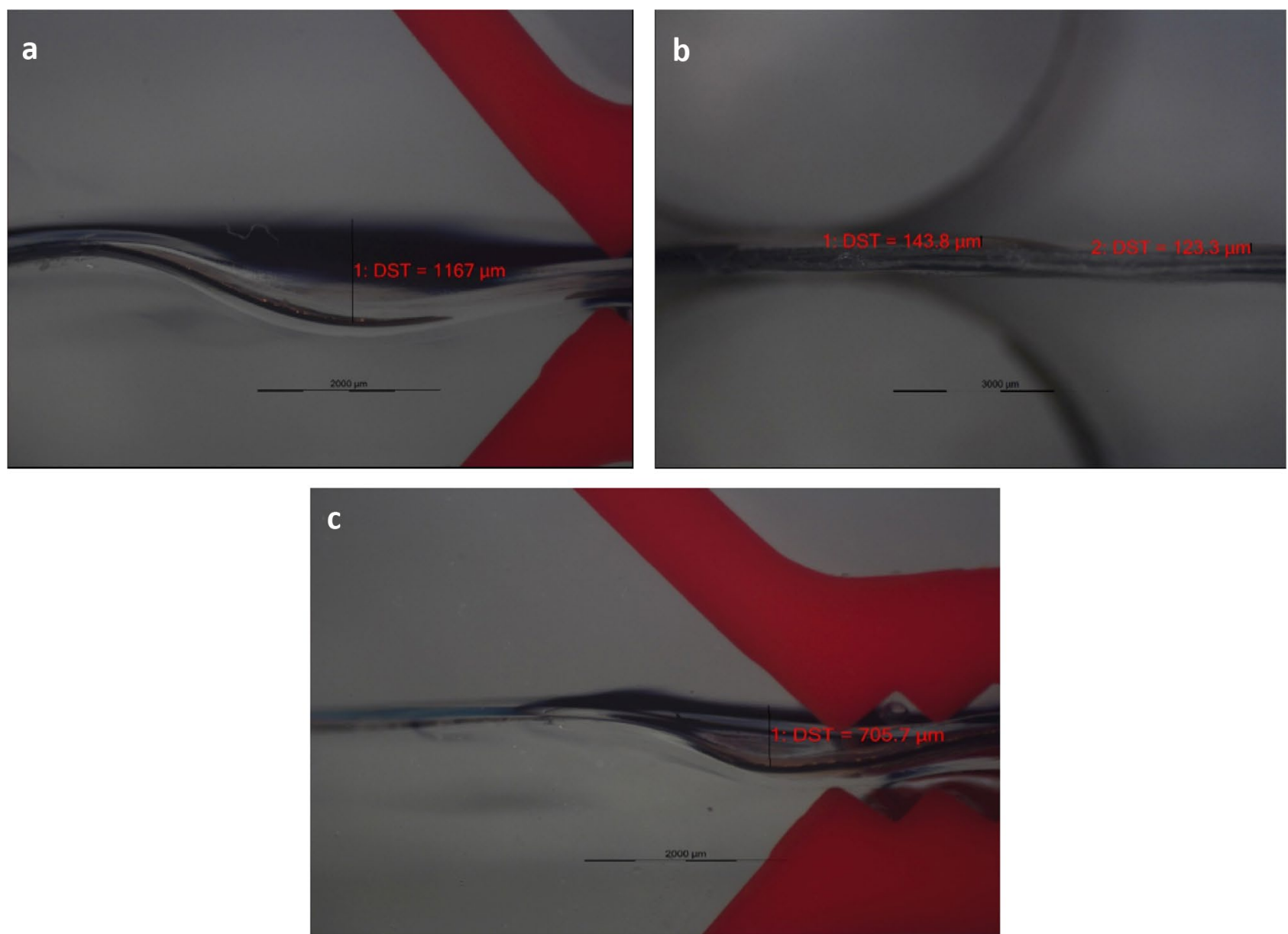

Fig. 19 Measurements done by an optical microscope on the crosssectional view of the three designs: (a) Out-of-plane measurement of the horseshoe-shaped meander. (b) Out-of-plane measurement of the fractal-shaped meander. (c) Out-of-plane measurement of the combination meander
Fig. 20 Correspondence between simulation and experimental results. There is a correspondence between the location of the maximum (calculated) stress and maximum (measured) out-of-plane deformation, which is mostly in the crest region of the meander. This is a qualitative indication of the validity of the model
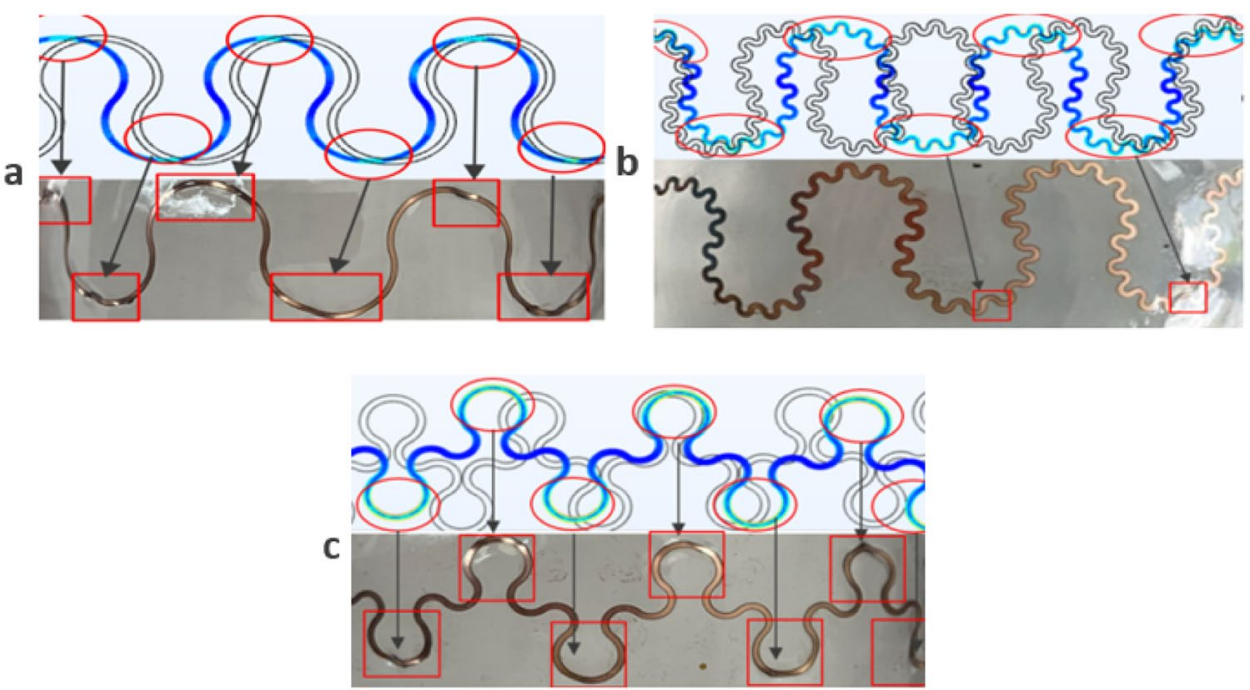
Fig. 21 Thermoforming results of a relevant paper and our experimental result: (a) [3] thermoformed sample by a semi-sphere mold, still with out-of-plane deformation. (b) Our thermoformed piece by a similar semi-sphere mold, without out-of-plane deformation (a) Previous paper

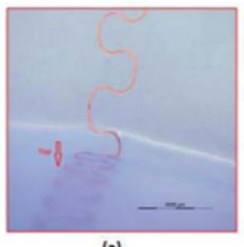

(a)

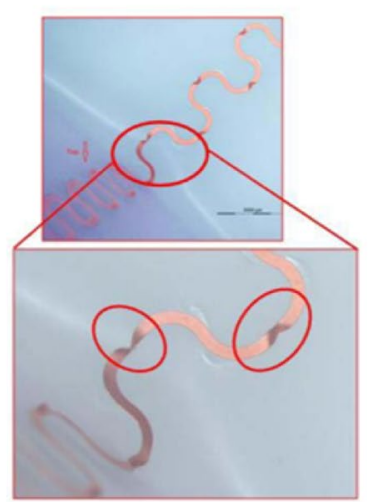

(b) Our design

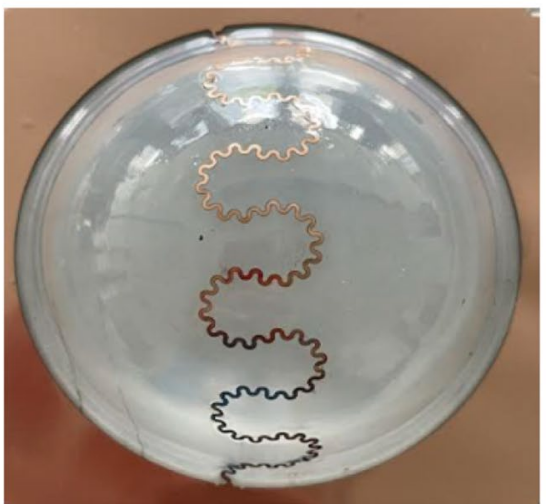

von Mises stress correspond to the observed out-of-plane (Fig. 20). Visible buckling is observed in the crests and troughs of the meander. Based on the linear buckling simulation, we have the simulated values for the maximum surface displacement for each meander shape, which is directly proportioned to the out-of-plane. We have compared the linear buckling simulation with the measured value with the optical micrometer (Table 6).

\subsection{Improvement with respect to the existing literature}

In [3], different meander shapes were investigated to find the best stretchability of the metallic interconnects in thermoformed electronics. Elliptical shape, horseshoe shape, and U-shaped meanders were studied in thermoforming experiments. Furthermore, various radii and copper widths were analyzed to find the best design parameters for the horseshoeshaped meander. In the end, none of the designs could accommodate the stretching caused by thermoforming without having out-of-plane deformation. Figure 21 represents a comparison of a relevant paper, and our experimental results confirm we have improved the design process of metallic interconnects for thermoformed electronics compared to other literature.

\section{Conclusion}

In conclusion, a fabrication and geometry-based approach was proposed to reduce out-of-plane buckling due to elongation of in-plane non-straight (meandered) metal interconnects. An optimal analytical design approach is introduced for fractal meander design parameters. We investigated different copper and polyimide thicknesses and polyimide widths to find the best design parameters for meander fabrication. Analytical calculations and finite element simulations were used to show the improvement of out-of-plane buckling and stress distribution in fractal designs compared to the standard horseshoe-shaped meanders. Two case studies were investigated based on the design approach. The results show that out-of-plane deformation is reduced to a $200 \mu \mathrm{m}$ scale using these fractal structures. Future studies can focus on higher elongation and optimizing fabrication parameters by using different conductive materials.

Nomenclature $L_{\text {segment }}:$ The length of asection of horseshoe meander; $R$ : The radius of the meander structure; $\theta$ : Meander opening angle; $H$ : The total height of the stretchable interconnection; $L_{\text {Axial }}$ : The period/pitch of themeander in non-stretched condition; $E$ : Elongation of the meander, which means the proportion of the finallength of the meander after it is fully stretched to the axial length of themeander; $D$ : $\mathrm{D}$ is the minimum distance between two adjacentmeanders; $\theta_{\text {Max }}:$ The $\theta$ which maximizes $E ; E_{f}$ : Elongation of the fractal meander, which means the proportion of thefinal length of the fractal meander after it is fully stretched to the axiallength of the fractal meander; $R_{f}$ : The radius of the fractal meander structure; $L_{\text {segment }-f}:$ The length of asection of fractal meander; $L_{\text {Axial }-f}$ : The period/pitch ofthe fractal meander in non-stretched condition; PI: Polyimide; $\mathrm{Cu}$ : Copper; FEM: Finite Element Model; SMI: Stretchable Mold Interconnect; FR4: A composite material composed of wovenfiberglass cloth with an epoxy resin binder that is flame resistant

Funding The research is done the in frame of my $\mathrm{PhD}$ and aEuropean project called "Smart@surface"

Data availability All the simulations are available up request. Thesimulation are done with COMSOL software.

\section{Declarations}

Ethics approval Not applicable.

Consent to participate Not applicable.

Consent for publication All the authors are agree to the publication of theseresults

Conflicts of interest/Competing interests Not applicable 
Open Access This article is licensed under a Creative Commons Attribution 4.0 International License, which permits use, sharing, adaptation, distribution and reproduction in any medium or format, as long as you give appropriate credit to the original author(s) and the source, provide a link to the Creative Commons licence, and indicate if changes were made. The images or other third party material in this article are included in the article's Creative Commons licence, unless indicated otherwise in a credit line to the material. If material is not included in the article's Creative Commons licence and your intended use is not permitted by statutory regulation or exceeds the permitted use, you will need to obtain permission directly from the copyright holder. To view a copy of this licence, visit http://creativecommons.org/licenses/by/4.0/.

\section{References}

1. Merilampi S, Björninen T, Haukka V, Ruuskanen P, Ukkonen L, Sydanheimo L (2001) Microelectron. Reliab 2010:50

2. DuraTech (2019) In-mold electronics (IME). Retrieved 30 Nov 2019. From https://www.duratech.com/capabilities/ime-inmold-electronics

3. Chtioui I (2016) Arbitrarily Shaped Rigid and Smart Objects Using Stretchable Interconnections, IEEE transactions on components packaging and manufacturing technology

4. Plovie B (2017) Arbitrarily shaped 2.5D circuits using stretchable interconnects embedded in thermoplastic polymers. Adv Eng Mater 19(8):1700032
5. Gonzalez M (2008) Design of metal interconnects for stretchable electronic circuits. Microelectron Reliab 48:825-832

6. Hsua YY (2009) In situ observations on deformation behavior and stretching induced failure of fine pitch stretchable interconnect. J Mater Res 24(12)

7. Hsu YY (2011) Polyimide-enhanced stretchable interconnects: Design, fabrication, and characterization, IEEE transactions on electron devices $58(8)$

8. Xu S (2013) Stretchable batteries with self-similar serpentine interconnects and integrated wireless recharging systems. Nature communications. https://doi.org/10.1038/ncomms 2553

9. Ma Q (2016) Mechanics of fractal-inspired horseshoe microstructures for applications in stretchable electronics. J Appl Mech 83

10. Biswas S (2018) Stress-adaptive meander track for stretchable electronics. Flex Print Electron 3:032001

11. Plovie B (2019) Design automation of meandered interconnects for stretchable circuits, IEEE transactions on computer-aided design of integrated circuits and systems 38(9)

12. Zhang Y (2013) Buckling in serpentine microstructures and applications in elastomer-supported ultra-stretchable electronics with high areal coverage. Soft Matter 9(33):8062-8070

Publisher's Note Springer Nature remains neutral with regard to jurisdictional claims in published maps and institutional affiliations. 